\title{
IDENTIDADE: COLONIZAÇÃO DO MUNDO DA VIDA E OS DESAFIOS PARA A EMANCIPAÇÃO
}

\author{
IDENTIDAD: COLONIZAZIÓN DEL MUNDODE LA VIDA YLOSDESAFÍOS A
}

LA EMANCIPACIÓN

IDENTITY: COLONIZATIONOF THE LIFEWORLD AND THE CHALLENGES FOR THE EMANCIPATION

http://dx.doi.org/10.1590/1807-0310/2017v29171283

Nadir Lara Junior e Andrea Paula Santos Lara

Universidade de São Paulo, São Paulo/SP, Brasil

\section{RESUMO}

O objetivo deste artigo é fazer uma apresentação teórica do conceito de identidade na obra de Antonio da Costa Ciampa e, em seguida, demonstrar como a colonização do mundo da vida causa entraves para que ocorra o sintagma (identidade-metamorfose-emancipação). Para tanto, partiremos de uma breve contextualização de como essa obra se inicia no Brasil, depois uma apresentação da conceituação de identidade e, por fim, um debate contemporâneo sobre o mundo da vida e sua colonização, processo no qual as dificuldades criadas podem constituir identidades fetichizadas.

Palavras-chave: mesmice; mesmidade; inclusão perversa; psicologia social.

\section{RESUMEN}

El objetivo de este artículo es hacer una presentación teórica del concepto de Identidad en la obra de Antonio da Costa Ciampa y demonstrar como la colonización del mundo de la vida causa obstáculos en el sintagma "Identidad-metamorfosis-emancipación" Para ello, partiremos de un breve contexto de cómo la obra se inició en Brasil, después de una presentación de la concepción de la Identidad y por último, un debate contemporáneo sobre el Mundo de la Vida y su colonización y por su vez, las dificultades creadas que en ese proceso pueden constituir identidades fetichizadas.

Palabras-clave: mesmice; mesmidad; inclusión perversa; psícologia social.

\begin{abstract}
The aim of this article is to make a theoretical presentation of the concept of identity in the work by Antonio da Costa Ciampa and then to demonstrate as the colonization of the worldlife cause hamper so that there takes place the sintagma (identity metamorphosis-emancipation). For so much, we will leave from a brief contextualization of as this work begins in Brazil, then a presentation of the conceptualization of the identity and for end a contemporary discussion on the worldlife, and its colonization, in which the dificulties create in this process can constitute identities fetishised.
\end{abstract}

Keywords: sameness; «mesmidade»; perverse inclusion; social psychology. 


\section{Introdução}

Refletir sobre a proposta de Antonio da Costa Ciampa é estar diante de um trabalho inédito, importante e que merece nosso reconhecimento, pois contribui sobremaneira para o estudo sobre a identidade, dialogando com a Psicologia Social brasileira e a realidade de nosso país. Interessante notar que a perspectiva de identidade como metamorfose e depois acrescentando a ideia de emancipação, Ciampa abre um pressuposto importante para dizer que a pessoa em sua história de vida, mesmo diante da pobreza e da violência, não se rende ou se entrega facilmente às adversidades.

Por isso, o objetivo deste artigo é fazer uma apresentação teórica do conceito de identidade na obra de Antonio da Costa Ciampa e depois demonstrar como a colonização do mundo da vida causa entraves para que ocorra o sintagma (identidade-metamorfoseemancipação). Para tanto, partiremos de uma breve contextualização de como essa obra inicia no Brasil, em uma realidade social marcada por muita pobreza e violência, que se acentua com a ditadura militar (1964 -1985). Nesse período, também os psicólogos sociais brasileiros e latino-americanos buscavam desenvolver uma perspectiva psicológica crítica e comprometida politicamente com a emancipação do país e das pessoas.

Em seguida, apresentaremos o modo como a sociabilidade e o reconhecimento se articulam à proposta de identidade de Ciampa. Veremos nessa parte que mesmice, mesmidade, identidade fetichizada e reconhecimento perverso são perspectivas decorrentes dessa articulação, nos dando assim alguns referentes das principais bases teóricas do conceito de identidade elaborado por Antonio da Costa Ciampa.

Na terceira parte, trataremos do tema "políticas de identidade e identidades políticas e reconhecimento". Veremos que as teorias de Axel Honneth e Erving Goffmann, assim como a de Ciampa, tomam como base comum ideias de George Herbert Mead e, assim, estigma, políticas de identidade e reconhecimento se articulam na proposta de identidade lançada por Ciampa.

Por fim, propomos um debate contemporâneo sobre a constituição da identidade numa sociedade marcada pelo conflito entre o mundo da vida e o sistema. A predominância do sistema, segundo Habermas, provoca a colonização do mundo da vida, provocando nas pessoas sérias dificuldades para acessá-lo e, na perspectiva de Ciampa, lançando o sujeito para a mesmice.

\section{Contextualização da obra de Ciampa}

Dessa forma, destacamos que no livro Novas veredas da Psicologia Social, organizado por Silva Lane e Bader Sawaia (2006), há diversos relatos dos/ das pioneiros/as da Psicologia Social no Brasil. Esses relatos remontam às experiências de psicólogos(as) das décadas de 1970 e 1980 e início de 1990 . Nessa obra, podemos perceber como estava sendo produzida uma psicologia fora da clínica tradicional e dos moldes da psicologia positivista. Gestava-se ali uma psicologia social latino-americana e brasileira.

A partir dos 80 instaurou-se um debate importante nas Ciências Sociais e na Psicologia Social a respeito dos grupos organizados politicamente. Interessante perceber na obra organizada por Lane e Sawaia (2006) que os relatos dos autores trazem como ponto comum, que unia todas as experiências dos psicólogos brasileiros nas mais diversas realidades, o trabalho realizado nos grupos e comunidades. Dessa forma, a práxis do psicólogo social estava intrinsecamente ligado aos processos grupais.

Nesse contexto, o debate se centrava na dimensão da organização comunitária (Lane \& Sawaia, 2006), a análise dos processos grupais em grupos populares, depois movimentos populares e, por fim, se consagra a nomenclatura de movimentos sociais, especialmente na década de 1990, na qual os movimentos populares não estavam somente se organizando por classe social, mas também por processos identificatórios de acordo com demandas específicas de gênero, raça, ecologia etc. Dessa maneira, a análise dos movimentos sociais foi se tornando importante no cenário da Psicologia Social.

Nesse sentido, podemos perceber que a produção de conhecimento na Psicologia Social tinha uma predominância na análise dos processos grupais. Por outro, em 1986, Antonio da Costa Ciampa defendeu sua tese de doutorado na PUC-SP e já no ano seguinte, 1987, sua tese foi lançada como livro: A estória do Severino e a História da Severina: um ensaio de Psicologia Social.

A tese de Ciampa enfocava justamente a questão da identidade do sujeito e não dava especial destaque aos processos grupais como os demais trabalhos de sua época. Essa originalidade na pesquisa de Ciampa logo chama a atenção da comunidade acadêmica, pois com seu referencial teórico conseguia demonstrar como o sujeito se constituía na relação com a sociedade e sua constituição não era simplesmente uma decorrência de processos biológicos, como outras psicologias apontavam. A tese de Ciampa convergia para uma profunda relação entre sujeito e sociedade, 
O sujeito enfocado por Ciampa em seus estudos sobre a identidade buscava formas de se emancipar da opressão. Portanto, esse autor trazia para as perspectivas de estudo dos processos grupais da Psicologia Social brasileira a dimensão da individualidade de cada pessoa diante de seus grupos (Lima, 2014).

A proposta teórica de Ciampa, obviamente, não é individualista, ou essencialista, tampouco diz que a pessoa se emancipa sozinha ou prescinde do coletivo. Ao contrário, se usando da teoria de George Herbert Mead, Erving Goffmann, Jürgen Habermas e Axel Honneth, propõe um sujeito que se faz nas relações sociais, na cultura, na coletividade, mas sem perder de vista a dimensão subjetiva.

Vale destacar que essa proposta de identidade, a partir da narrativa de história de vida, aponta para uma concepção de pessoa que está sempre em luta por emancipação. Portanto, sua ontologia não pressupõe alguém estático, parado, encerrado em si mesmo, um solipcista. Lendo a obra de Ciampa, somos convidados a pensar não somente sobre as dificuldades e as agruras de nossa sociedade, mas temos que olhar e valorizar os sujeitos que, de alguma forma, buscam novas possibilidades para suas vidas.

A linguagem poética de Ciampa demonstra uma sensibilidade ao olhar com cuidado para a história das pessoas, valorizando uma ética do cuidado com a vida de cada sujeito, sendo assim esse autor se torna fiduciário das origens da Psicologia Social brasileira, historicamente comprometida com a vida das pessoas mais empobrecidas e oprimidas por regimes políticos que prezam pela exclusão social.

\section{Sociabilidade, identidade e reconhecimento}

Em sua obra $A$ estória do Severino e a História da Severina: Um ensaio de Psicologia Social, Antonio da Costa Ciampa (2001) apresenta a ideia de que o sujeito é uma representação de um momento histórico, é parte do tempo, do lugar, da família de origem e da vida que vive. Nessa obra, esse autor compreende de maneira idiossincrática o ser humano, pois supõe que a identidade se constitui como metamorfose e dessa maneira atribui certa dinamicidade a esse conceito demonstrando que a pessoa não pode ser reduzida aos estereótipos que lhe são atribuídos. Com essa lógica, Ciampa contraria as teorias vigentes até a década de 1980 que entendiam a identidade como algo estático e/ou controlada por estímulos e reforços positivos ou negativos.

Ciampa (2001) considera a importância das relações sociais na sua concepção de identidade e afirma que ao compreendê-la se compreende a relação do indivíduo com a sociedade. A partir da elaboração das ideias de Ciampa acerca da identidade como metamorfose humana, essa passou a ser entendida como um conceito central para a Psicologia Social, que, conforme afirma Lima (2010), "poderia ajudar a explicar tanto como se dava a construção das desigualdades e dos problemas sociais quanto entender como se formavam as resistências individuais aos processos de massificação e as buscas emancipatórias" (p. 138).

Antonio da Costa Ciampa (2001) em sua obra A estória do Severino e a História da Severina: Um ensaio de Psicologia Social analisa dois personagens, um pertencente à ficção (Severino é personagem do poema Morte e Vida Severina, de João Cabral de Melo Neto) e outro pertencente à vida real (Severina). A partir da análise desses dois personagens, Ciampa consegue demonstrar que na singularidade está também a totalidade, como afirma Lane (1987, p. 10): "Chega à identidade como metamorfose desvendando a ideologia da não transformação do ser humano como condição da não transformação da sociedade."

Ciampa afirma que a forma de expressão da identidade como metamorfose acontece por meio de personagens que cada um "representa" socialmente; nesse sentido "podemos dizer que as personagens são momentos da identidade, degraus que se sucedem, círculos que se voltam sobre si em um movimento, ao mesmo tempo, de progressão e de regressão (2001, p. 198).

Dessa forma, cada indivíduo apresenta-se como representante de si mesmo e ator de diferentes personagens, que se articulam e se revezam perante os outros, e a articulação dessas personagens é a expressão do Eu, sendo impossível que o indivíduo se apresente em sua totalidade, pois a cada momento está representando um personagem diferente, pertencente aos muitos personagens que compõem sua identidade.

Nesse aspecto, Lima (2010) afirma que "a concepção de personagem desenvolvida por Ciampa mostra-se muito próxima da ideia meadiana de articulação do 'eu' com vários 'mim(s)' (p. 144), em que a relação entre o 'eu' e o 'mim' seria semelhante ao relacionamento entre parceiros de um diálogo.

Nessa perspectiva, estamos sempre representando a nós mesmos diante do outro e, ao contar uma história, precisamos sempre de personagens, ou seja, somos todos eternos personagens de nossa história e o outro com o qual me relaciono também é um personagem, e juntos construímos outra história, e, quando não há mais personagens para representar, o ator caminha para a morte: 
Como é obvio, as personagens são vividas pelos atores que as encarnam e que se transformam à medida que vivem suas personagens. Enquanto atores estamos sempre em busca de nossas personagens; quando novas não são possíveis, repetimos as mesmas; quando se tornam impossíveis tanto novas como velhas personagens, o ator caminha para a morte, simbólica ou biológica. (Ciampa, 2001, p. 157)

O autor acima define ainda que identidade seja, ao mesmo tempo, diferença e igualdade com relação aos outros, é ainda algo que une a subjetividade e a objetividade, pois, "sem essa unidade, a subjetividade é desejo que não se concretiza, e a objetividade é finalidade sem realização" (Ciampa, 2001, p. 145).

Além disso, há ainda o aspecto mais importante na definição de identidade apresentada por Ciampa (2001): a metamorfose - um processo que ocorre desde o nascimento do indivíduo até o momento de sua morte, ou seja, o ser humano não é, ele está sendo, como o vir-a-ser descrito por Heráclito, que é movimento, algo que está se constituindo o tempo todo, como uma obra sempre inacabada.

O autor afirma também que não é possível dissociar o estudo da identidade do indivíduo do estudo da sociedade, pois o indivíduo não pode deixar de ser social e histórico. Se por um lado, o ser humano não está limitado em um vir-a-ser determinado (como uma semente, que tem como destino ser árvore), por outro lado, também não está liberado das condições históricas em que vive; desse modo, seu vir-a-ser não é uma indeterminação absoluta.

Para Ciampa, a identidade é movimento de transformação, é metamorfose. Esse movimento de transformação tem um sentido para o indivíduo que se apresenta por meio de seus diversos personagens, pois ele se apresenta sempre a outro do qual espera o reconhecimento de suas personagens; nesse sentido, Almeida (2005, p. 85) afirma:

Em cada contexto, o indivíduo expressa sua pretensão de ser reconhecido como determinada pessoa (que supõe ou procura ser) e é reconhecido ou não (conforme o que os outros pressupõem que ele seja). Em cada contexto, ele é o que está sendo para si e para os outros, ou seja, sua subjetividade incorpora (de modo conformista ou conflitivo a intersubjetividade, pois está agindo sempre levado em consideração às expectativas dos outros e às pretensões de si mesmo.

Nesse mesmo sentido, Lima (2010) afirma que é na tese de Ciampa que aparece a proposição da identidade como metamorfose. Nessa perspectiva, delineiam-se duas afirmações relacionadas à questão do reconhecimento: a primeira afirmação do autor é que o desenvolvimento da identidade trata-se de uma sequência de formas de reconhecimento, e a segunda proposição afirma que, quando esse reconhecimento é ausente ou feito de forma desumana, os indivíduos vivenciam a experiência do aprisionamento à "mesmice", ao fetiche de uma personagem que impede a concretização do sentido emancipatório da identidade.

Essa pretensão de ser alguém frente aos outros é sempre confrontada com as pressuposições acerca de quem os outros (sociedade) esperam que o indivíduo seja, há sempre uma identidade pressuposta, ou seja, uma determinação externa ao indivíduo sobre a qual ele pode agir no sentido de reproduzir ou modificar tal pressuposição.

Um exemplo de identidade pode clarear essa noção de identidade pressuposta. Antes de nascer, o nascituro já é representado como filho de alguém e essa representação prévia o constitui efetivamente, objetivamente como filho, membro de uma determinada família, personagem (preparada para um ator esperado) que entra na história familiar às vezes até mesmo antes da concepção do ator. Posteriormente essa representação é interiorizada pelo indivíduo, de tal forma que seu processo interno de representação é incorporado na sua objetividade social, como filho daquela família. (Ciampa, 2001, p. 161)

O indivíduo necessita repor sua identidade cotidianamente para que possa apresentar-se como o que está sendo, ele repõe no presente o que tem sido até então, confirmando sua imagem diante dos outros, ou, como afirma Almeida (2005), "ele re-apresenta sua identidade: aquilo que representa hoje é igual a aquilo que representou ontem e que se espera que represente amanhã".

É o que Ciampa (2001,p. 165) chama de aparência de não transformação, mas é apenas aparência, pois, como o mesmo autor afirma, qualquer objeto mesmo mineral ou vegetal, deixado à sua própria natureza, transforma-se.

$\mathrm{Na}$ verdade, evitar a transformação - manter-se inalterado - é impossível; o possível, e que requer muito trabalho, é manter alguma aparência de inalterabilidade, por algum tempo, como resultado de muito esforço para conservar uma condição prévia, para manter a mesmice.

Esse trabalho de reposição na tentativa de evitar a transformação cria a aparência de uma identidade atemporal, imutável, fixa, que é chamada por Ciampa (2001) de "mesmice" e, embora seja frequente no convívio social, pode ter como consequência, 
em muitas situações, a paralisia da ocorrência de novas identificações e, assim, impedir o processo emancipatório.

Esse movimento, que é decorrente da reposição da identidade, pode ocorrer como uma busca de estabilidade da identidade ou por compulsão à repetição. A mesmice coloca o indivíduo em uma condição aparentemente atemporal de repetir sempre o mesmo personagem, processo que é chamado por Ciampa de fetichismo da personagem.

O fetiche da personagem é percebido como um aprisionamento no mundo da mesmice, ou seja, mesmo que a atividade que engendra a personagem deixe de ser desempenhada, a representação da personagem persiste. Podemos exemplificar isso com a afirmação presente na obra de Ciampa (2001) "Severino é lavrador, mas já não lavra": a atividade continua determinando o personagem, mesmo não havendo mais o exercício dessa atividade.

No entanto, a mesmice não é necessariamente prejudicial ao indíviduo, Almeida (2005, p. 92) esclarece que a reposição também pode expressar nossas necessidades, servindo de base para lidar com a alteridade e sendo uma forma de resistência no mundo.

Nem sempre o processo de reposição da identidade expressa alienação e heteronomia. Com efeito, ele pode ser fruto de uma atitude positiva frente à vida específico, que se considera suficientemente válido e digno de manter. ... O que se preconiza, então, é que os indivíduos não se transformem em prisioneiros do que estão sendo ou têm sido, de seus papéis ou das situações que vivenciam ... . Os papéis representados não podem ser tratados como uma realidade absoluta da pessoa. Ao contrário, admitida a identidade como metamorfose, os seres humanos devem ser considerados do ponto de vista de sua potência, seres capazes de ultrapassar limites, considerados esses limites não como um término. (Almeida, 2005, p. 92)

Outra possibilidade de movimento da identidade é o que Ciampa (2001) chama de "mesmidade", que é o processo de busca de transformação do indivíduo. Essa definição deriva da ideia do "Eu" proposta por Mead (1973) e já mencionada anteriormente. Essa é a parte da personalidade que possibilita a criação de novas alternativas de ação.

Em interação com suas diferentes personagens, a pessoa procura reproduzir valores e símbolos sociais a partir de sua análise interna e criar novas atitudes, crenças e ideias que podem dar origem a novos personagens. Esse movimento provoca a necessidade da busca de novas maneiras de se relacionar com o mundo e, em alguns casos, é capaz de modificar a teia social.
Segundo Lima (2009), o conceito de Identidademetamorfose apresentado por Antonio da Costa Ciampa foi ampliado após 1999, quando o autor propõe o sintagma identidade-metamorfose-emancipação:

Mais do que simplesmente incorporar a palavra "emancipação" aos já associados identidademetamorfose, essa proposição indica que o autor assume que pesquisar identidade é buscar compreendêla em toda sua abrangência e complexidade (cognitivo, afetivo, estético, moral, sexual, corpóreo, motor etc.). É considerar como pressuposto que o indivíduo, à medida que vai adquirindo a capacidade de agir e de falar, vai também passando a se reconhecer e a ser reconhecido como alguém que pode afirmar "eu" de si mesmo. Nessa guinada, incorpora-se a perspectiva habermasiana de que a constituição do humano, a subjetividade do indivíduo, é vista sempre articulada com a objetividade da natureza, a normatividade da sociedade e a intersubjetividade da linguagem. (Lima, 2009, p. 136)

Segundo Siebeneichler (2003), para Habermas a emancipação está diretamente relacionada ao processo de conquista e manutenção de autonomia, e é com base nessa premissa que consideramos, assim como para Ciampa, que muitas das metamorfoses vivenciadas pelos sujeitos são direcionadas à emancipação; consideramos ainda que o jogo do reconhecimento e não reconhecimento presentes ao longo da história de uma pessoa proporciona condições para que tais metamorfoses ocorram.

É com base nesse sintagma que se buscam aspectos da identidade dos sujeitos em pesquisas desenvolvidas com essa perspectiva teórica, porque se identifica não somente seus principais personagens envolvidos com o tema pesquisado, mas também o sentido de suas metamorfoses, bem como suas possibilidades de busca por emancipação.

É importante enfatizar que a necessidade de reconhecimento (Honneth, 2003) faz parte do desenvolvimento da identidade humana, e a ausência ou distorção desse reconhecimento tem como consequência o aprisionamento à "mesmice", que impede a concretização do sentido emancipatório da identidade.

Segundo Lima (2010, p. 147), "O jogo do reconhecimento faz com que a identidade seja sempre pressuposta, abrindo o precedente para que ela seja reposta". Essa posição e reposição da identidade mencionadas pelo autor podem ser tanto positivas quanto negativas, uma vez que é o resultado da articulação que o indivíduo faz com o que fizeram/ fazem dele em todos os momentos de sua vida, podendo constituir movimentos de mesmice ou 
mesmidade, levando o indivíduo a movimentos que podem ser emancipatórios ou a um aprisionamento em personagens-mito:

\begin{abstract}
Daí a expectativa generalizada de que alguém deve agir de acordo com suas predicações e, consequentemente, ser tratado como tal. De certa forma, reatualizamos através de rituais sociais, uma identidade pressuposta, que assim é vista como algo dado (e não como se dando continuamente através da reposição). Com isso retira-se o caráter de historicidade da mesma, aproximando-a mais da noção de um mito que prescreve as condutas corretas, reproduzindo o social. (Ciampa, 2001, p 163)
\end{abstract}

Na obra de Ciampa, podemos perceber a importância do reconhecimento do outro para o desenvolvimento da identidade quando Severina, que sempre foi considerada não humana por todos e é tratada com respeito e credibilidade, primeiro por um patrão e depois pelos colegas de uma organização budista. Ao ser reconhecida em sua humanidade, Severina pode abandonar seus personagens fetichizados e reconhecerse como humana; ao abandonar a mesmice, pode metamorfosear-se em outra pessoa sem deixar de ser ela mesma.

\section{Estigma, políticas de identidade e reconhecimento}

Ciampa (2002), ao tratar do tema políticas de identidade e identidades políticas, analisa as afirmações de Goffman sobre os discursos que podem ser apresentados para o estigmatizado e vê que neles o autor afirma que há um discurso com predominância da fraseologia psiquiátrica (no exogrupo) e outro, com predominância de fraseologia política (no intragrupo). Goffman (1988, p. 134) apresenta a expressão "política de identidade" e afirma que nela ocorre uma orientação ao estigmatizado com a qual é dito que "se ele adotar uma linha correta (linha essa que depende da pessoa que fala), ele terá boas relações consigo e será um homem completo, um adulto com dignidade e autorrespeito". Nesse sentido, Ciampa (2002) analisa essa afirmação de Goffman, dizendo que:

Tais observações mostram como essa questão de políticas de identidade desde o início envolve um conflito entre autonomia e heteronomia, em pelo menos dois pontos. Em um, entre a suposta autonomia do discurso do intragrupo (com fraseologia predominantemente política) e a heteronomia do discurso do exogrupo (com fraseologia que Goffman chama de psiquiátrica, mas que poderíamos também chamar de paternalista ou assistencialista, quando não colonizadora). (Ciampa (2002, p. 3)
Em nosso entendimento, fica evidente que, ao impor uma "linha correta" de conduta definida de forma heterônoma - do ponto de vista de outra pessoa, que impõe ao estigmatizado certas condições para que ele possa ser "aceito" socialmente, ocorre uma aceitação perversa que impõe ao indivíduo estigmatizado ocupar lugares previamente definidos pelos "normais". Esses lugares, muitas vezes, possuem limites muito claros, ou seja, não são lugares onde possa existir a expressão livre da identidade da pessoa estigmatizada, mas apenas a representação de papéis preestabelecidos.

Essas políticas de identidade que visam conformar o diferente a uma linha traçada pelos "normais" levam o indivíduo estigmatizado a uma percepção distorcida de si mesmo, ou, como afirma Goffman (1988, p. 134): "na verdade ele terá aceitado um eu para si mesmo; mas esse eu é... um habitante estranho, uma voz do grupo que fala por e através dele.”.

Como vimos anteriormente, Ciampa (2001) considera que a identidade pressuposta surge a partir de determinações heterônomas com as quais o indivíduo se identifica, ou seja, a identidade pressuposta surge das expectativas por parte dos outros (sociedade) acerca de como deve ser um determinado indivíduo, então, tratase de uma determinação externa, no entanto, o autor afirma que o indivíduo sempre pode agir no sentido de reproduzir ou modificar tal pressuposição, pois ele não é apenas um cidadão, um membro da comunidade, ele reage também a essa comunidade e a transforma com suas reações.

No mesmo sentido, Mead (1973) também menciona a possibilidade de ação do indivíduo sobre o que lhe é determinado socialmente quando descreve os componentes do self-o "Eu" e o "Mim": enquanto este consiste na reprodução das regras sociais, exprimindo adaptação, o Eu é a reação do sujeito às ações da sociedade, à expressão de novas atitudes.

Honneth (2003) afirma que essa inserção do indivíduo na sociedade organizada dentro do domínio de experiências de cada indivíduo envolvido ou incluído nesse todo é a base para o desenvolvimento pleno da identidade do indivíduo. O autor afirma ainda que, ao aprender a assumir as normas sociais de ação do "outro generalizado", o sujeito pode alcançar a identidade de um membro socialmente aceito em sua coletividade.

Ciampa (2001) lembra que, embora sempre exista a possibilidade de um agir autônomo diante das determinações sociais, há uma possível confusão entre a questão da autonomia e a questão da autenticidade: "como definir quando se trata de uma escolha original e autêntica do próprio indivíduo?" (p. 3); ou quando 
podemos saber que o discurso (ou ação) do indivíduo não é apenas uma reprodução de algo que pertence a uma determinada massa e, portanto, trata-se de um "ajuste do próprio ego à imagem e semelhança do 'outro"”? (p. 3).

Esse autor lembra que, ao postular a malignidade das massas, corremos o risco de retirar a legitimidade de qualquer ação ou discurso autônomo do intragrupo, mas, ao mesmo tempo, proclamar a necessidade sempre de um controle externo é só admitir como legítima a heteronomia decorrente da ação e do discurso do exogrupo.

Ciampa afirma que as políticas de identidade estão presentes em todos os setores da sociedade, embora a maioria dos estudos acerca de políticas de identidade faça menção a grupos com identidades discriminadas, marginalizadas ou oprimidas por setores dominantes. Não podemos ignorar a existência de políticas de identidade também em setores dominantes e/ou elitizados da sociedade, onde apenas os "personagens" (ou psiques de massa) são diferentes entre si, mas a articulação dessas "personagens coletivas" com a noção de identidade pessoal é a mesma em qualquer setor social:

Utilizando uma linguagem dramatúrgica, pode-se dizer que a política de identidade de um grupo ou coletividade refere-se de fato a uma "personagem" coletiva; fala-se tanto de um "branco" ou um "negro", quanto se pode falar de um "judeu", um "psicanalista", um "velho", um "jovem", um "corintiano", um "trabalhador", um "vagabundo" etc; como os exemplos estão no masculino, vamos incluir também um "homem", uma "mulher", lembrando que podemos fazer várias combinações: um "homem branco", uma "mulher negra" e assim por diante. (Ciampa, 2001, p. 4)

Esse autor afirma ainda que o estudo das políticas de identidade torna possível discutir a especificidade de lutas pela emancipação em diferentes grupos sociais, mas não é suficiente, pois não há como definir previamente o caráter emancipador de qualquer ação coletiva antes da constituição da identidade coletiva.

A identidade para Ciampa (2001) é quase sempre referida a uma personagem: "negro", "trabalhador", "mulher", "sem-terra", etc., a cada um correspondendo um ou mais movimentos, mas a questão que se apresenta para que possamos determinar o caráter emancipatório do movimento seria a de articular múltiplas personagens e assim constituir "uma identidade pessoal singular que pudesse também ser considerada uma identidade política?" (p. 6).

Para Honneth (2003), o engajamento individual na luta política restitui ao indivíduo um pouco de seu autorrespeito. Pensamos que esse engajamento, quando não se trata de um movimento motivado apenas de forma heterônoma, mas também como forma de superação das experiências individuais de desrespeito, pode levar a uma forma de identidade política, que, como afirma Honneth (2003), tem como efeito reforçativo a experiência de reconhecimento que a solidariedade do grupo político propicia, fazendo os membros alcançarem uma espécie de estima mútua.

Honneth (2003), em sua obra Luta por Reconhecimento, propõe um modelo teórico de análise da identidade fundada na concepção de reconhecimento de Hegel e na teoria da sociabilidade desenvolvida por Mead. Nessa obra, o autor sistematiza uma teoria do reconhecimento buscando fundamentar solidamente, a partir dos escritos do jovem Hegel, a ideia de que é a luta por reconhecimento que constitui a verdadeira gramática dos conflitos sociais. Honneth constrói a hipótese de que é a experiência de não reconhecimento (ou desrespeito) que leva à resistência social.

Segundo essa perspectiva, as lutas por reconhecimento ganham a dimensão de fundamento para os avanços normativos sociais. Esse autor propõe, a partir das proposições de Hegel, uma tipologia progressiva de formas de reconhecimento: amor, direito e solidariedade. A esfera do amor permite ao indivíduo uma confiança em si mesmo; na esfera jurídica, a pessoa individual é reconhecida como autônoma e moralmente imputável, desenvolvendo uma relação de autorrespeito; na esfera da solidariedade, a pessoa é reconhecida como digna de estima social, potencializando os projetos de autorrealização.

A esses três padrões de reconhecimento intersubjetivo correspondem três maneiras de desrespeito: a violação, a privação de direitos e a degradação; e é em resistência a essas formas de não reconhecimento que se desencadeiam os conflitos sociais, tendo-se muitas vezes como resultado sua gradativa superação ao longo da história.

A teoria de Honneth, assim como a de Ciampa, conflui com as ideias de Mead acerca do reconhecimento e da sociabilidade. Nessa perspectiva Honneth (2003, p. 125) nos traz a seguinte afirmação:

Em nenhuma outra teoria, a ideia de que os sujeitos devem sua identidade à experiência de um reconhecimento intersubjetivo foi desenvolvida de maneira tão consequente sob os pressupostos conceituais naturalistas como na psicologia social de George Herbert Mead.

Esse autor enfatiza que, em sua análise, Mead deixa claro que a consciência de si mesmo só pode surgir em um sujeito à medida que ele aprende a 
perceber sua própria ação da perspectiva de uma segunda pessoa, ou seja, é a partir do reconhecimento do outro que surge a autoconsciência.

\section{A colonização do mundo da vida e os entraves para o sintagma}

Portanto, o desafio contemporâneo de se pensar a questão da identidade vem sendo apresentado nos trabalhos de Lima $(2010,2014,2015)$ que, seguindo as pegadas de Ciampa, nos diz que mesmo diante das adversidades típicas de uma sociedade capitalista há sempre possibilidades de luta pela emancipação. As "narrativas de histórias de vida" nos mostram que ainda há pessoas fazendo sintagma: identidademetamorfose-emancipação, portanto, essa perspectiva sinaliza que esse não está totalmente determinado pelo sistema e que o mundo da vida ainda não foi totalmente colonizado, pois há possibilidades de mudança do sujeito e da sociedade.

Nesse aspecto, os esforços de Ciampa, Almeida (2005), Lima $(2010,2014,2015)$ e muitos outros pensadores dessa perspectiva teórica são para criticar as maneiras como a sociedade cria empecilhos para o sintagma, fazendo com que o sujeito recaia na mesmice. Eles se usam da crítica também para apontar possibilidades para que se constitua uma sociedade que saiba reconhecer e criar sociabilidades para que $o$ sujeito tenha mais acesso ao mundo da vida.

No entanto, os trabalhos de Lima (2010, 2014, 2015) vêm nos mostrar que a sociedade capitalista contemporânea causa diversos entraves para a vida das pessoas fazendo com que essas incorram no que Ciampa chamou de fetiche da personagem. Para aprofundar essa questão, Lima busca fundamento teórico em Jürgen Habermas e Axel Honneth sobre como a colonização da vida e o reconhecimento perverso se tornam os principais entraves para o sintagma.

Nesse sentido, Habermas (1999) irá nos mostrar uma oposição entre o "sistema" e o "mundo da vida", que acarreta uma desvinculação, por exemplo, entre a vida do trabalhador e seu trabalho, fazendo com que esse se vincule ao trabalho de maneira alienada e constituindo assim uma "mesmice", que o impossibilita de acessar o mundo da vida com mais frequência.

Por isso, Habermas (1999) nos dirá que a sociedade deve ser discutida sob a ótica de duas razões: a instrumental e a comunicativa, sendo que, com esta última, propõe um novo paradigma, que parte de uma crítica à razão instrumental weberiana e diverge para uma racionalidade pautada na comunicação, em busca do consenso intersubjetivo.
Habermas (1999) concebe o mundo da vida como a dimensão na qual impera a razão comunicativa, espaço das sensações, dos sentimentos, da comunicação, da cultura e do entendimento entre os sujeitos. Araújo e Cinalli $(2005$, p. 7), baseados em Habermas, nos dizem que "o mundo da vida é o ambiente cotidiano onde as pessoas agem e se defrontam com suas ações e reações, relações sociais, interpessoais e subjetivas"; em contraponto a esse mundo, o mundo sistêmico é a esfera do trabalho e do mercado, orienta-se pelas ações estratégicas e instrumentais, a razão instrumental é imperativa no mundo sistêmico.

Segundo Siebeneichler (2003, p. 25), "Habermas procura reagir contra o que chama de irracionalidade dominante na sociedade atual, interpretando-a num quadro macroscópico como manifestação do predomínio de uma racionalidade técnica, instrumental"; o autor percebe a irracionalidade atual como uma colonização do interior do mundo da vida, e a partir dessa análise reformula o antigo problema da reificação ou coisificação, em termos de patologia do mundo da vida induzida pelo sistema.

Nesse sentido, Freitag e Rouanet (1980) afirmam que Habermas descreve dois processos de transformação de conotação negativa: a dissociação e a racionalização. A dissociação implicou o "desengate" entre "mundo da vida" e sistema, que, segundo o autor, é quase irreversível em nossos tempos. A racionalização contaminou a economia e o Estado e se expandiu a diversas instituições do mundo da vida, isso leva Habermas a falar em "colonização" do mundo da vida pelo sistema.

Habermas (1999) atribui o que ele chama de "patologias da modernidade" a essa colonização, e a primeira patologia descrita pelo autor faz com que os sujeitos modernos submetam suas vidas às leis do mercado e à burocracia estatal, como se fossem forças estranhas contra as quais não há nada a fazer. Essa apatia generalizada reforça as tendências da dissociação, permitindo que a economia e o Estado sejam controlados por uma minoria, que determina as regras, sem consultar a maioria. A segunda patologia decorre da primeira, porque, à medida que o sistema se fortalece em detrimento do mundo da vida, ele passa a impor sua própria lógica e suas regras do jogo.

A colonização, portanto, refere-se à penetração da racionalidade instrumental e dos mecanismos de integração do dinheiro e do poder no interior das instituições culturais, ocupando, como tropas invasoras, os espaços privilegiados da razão comunicativa e substituindo-a pela razão instrumental.

Nesse sentido, Araújo e Cinalli (2005) afirmam que, para Habermas, o período no qual as tradições 
culturais, administrativas e produtivas reinavam era mais equilibrado que o momento em que a razão instrumental e econômica predomina, e o distanciamento do homem com relação aos mitos e às tradições faz com que se percam aspectos importantes como a espontaneidade e a criatividade.

No entanto, não podemos deixar de observar que sistema e mundo da vida não são passíveis de separação, não há uma maneira de excluir um ou outro da composição da sociedade. Podemos entender ainda que os seres humanos sejam influenciados em seu dia a dia por interferências dessas duas esferas, no entanto, o que Habermas aponta como a "colonização" do mundo da vida trata-se de uma anulação de aspectos referentes a esse mundo em decorrência do domínio da lógica sistêmica.

O reflexo dessa colonização do mundo da vida pelo sistema no mundo do trabalho é muito claro, sendo a já citada desvinculação entre a vida do trabalhador e seu trabalho o principal aspecto dessa influência; dessa forma, há uma cisão entre a "vida pessoal" e a "vida profissional", esfacelando-se os valores individuais, que são muitas vezes diversos e contraditórios com relação aos valores do mundo do trabalho.

Citamos aqui a dimensão do trabalho como um exemplo, visto que esse ainda toma uma grande parte da vida das pessoas e muito de suas identificações decorrem dessa relação. Nesse aspecto, pensamos que o mercado de trabalho na atualidade é regido por normas e valores muito particulares ditadas pelo que Sennett (1998) chamou de "capitalismo flexível", ou seja, um modelo de capitalismo que ataca qualquer forma de burocracia ou rotina e valoriza trabalhadores que sejam ágeis, estejam abertos a mudanças em curto prazo, assumam riscos continuamente e dependam cada vez menos de processos formais. Portanto, um sujeito que evita se vincular com qualquer valor ético ou moral; sentimentos a pessoas ou grupos, pois o que predomina é a fluidez das relações para poder se dedicar exclusivamente à personagem desenvolvida no mercado de trabalho.

Deste modo, a colonização do mundo da vida, atrelada a um capitalismo flexível, certamente influencia nas formas de subjetivação contemporâneas e com isso as possibilidades de emancipação do sujeito vão se tornando cada vez mais difíceis. Nesse sentido, Lima (2010) vai nos referir a um sofrimento de indeterminação e reconhecimento perverso como algo típico de uma sociedade capitalista e as formas de administração desse sistema tendem a dominar o sujeito a tal ponto que sofra por não saber como lutar por emancipação.
Nessa lógica, Lima (2010, p. 230), baseado em Ciampa, irá afirmar que "um reconhecimento perverso, reduz as infinitas possibilidades de criação das personagens à representação de uma identidade fetichizada, estigmatizada", sem possibilidades de "mesmidade", recaindo na "mesmice".

Habermas e Sennett nos alertam que a maneira pela qual as pessoas se identificam com os valores (capitalistas) e assim organizam suas vidas está provocando sérias dificuldades para o sujeito contemporâneo. Nessa lógica, Lima (2010) dirá que isso decorrerá numa identidade tendendo à mesmice e assim com sérias dificuldades em seu sintagma, pois como vimos anteriormente, Severina ao ser considerada não humana por todos sofre em sua situação de pobreza e descaso.

Diante desse cenário, a crítica cumpre a função de desmantelar formulações discursivas que trazem erros, ilusões, insinceridades e cinismos que se estruturam na sociedade capitalista e que, portanto, sustentam relações opressivas.

Por isso, criticar e apontar essas maneiras de como o mundo da vida está sendo colonizado, possibilita um reconhecimento dos entraves para o sintagma, para que assim possamos fazer um movimento de buscar uma "descolonização" do mundo da vida. Nesse sentido, Ciampa nos aponta possibilidades para isso, pois quando Severina passa a ser reconhecida em sua humanidade e tratada com respeito e credibilidade pelas pessoas, ela pode abandonar a mesmice, pode fazer seu sintagma, sem deixar de ser ela mesma.

\section{Considerações finais}

A questão da identidade debatida até aqui nos traz a dimensão da história da Psicologia Social brasileira: compromisso ético com os mais pobres; luta por emancipação; organização social e comunitária. Dessa maneira, pensamos que Antonio da Costa Ciampa apresenta para nós possibilidades de pensar a Psicologia Social numa perspectiva crítica e, até certo ponto, regada por uma dose de otimismo com relação à vida social que levamos.

Mesmo diante dos desafios da colonização do mundo da vida e do capitalismo flexível, a perspectiva teórica de Ciampa sempre aponta para uma saída que não é ingênua ou desnudada de crítica, muito pelo contrário, pois como citamos anteriormente, esse autor está vinculado a uma tradição da Psicologia Social brasileira que prima pela criticidade e pela ética do cuidado com as pessoas que sofrem com a opressão em nossa sociedade. 
Desta feita, o pensamento de Ciampa nos possibilita olhar um ser humano capaz de realizar um movimento para emancipação, mesmo em situações de colonização do mundo da vida; inclusão perversa. Isso o afasta de visões derrotistas e estigmatizantes que percebem as pessoas como um acumulado de doenças, deficiências e inconsistências e que só lhes restam fazer a "mesmice", seja pela condição de ser reconhecido como um incapaz ou pelos próprios efeitos da relação com as pessoas que reforçam essa posição.

Fazer sintagma na perspectiva desta teoria de Ciampa é colocar a pessoa sempre em busca de possibilidades para desfrutar da sua felicidade de abdicar a mesmice, e se metamorfosear em outra pessoa, preservando a si mesmo, não como essência, mas como condição de ser no mundo da vida.

\section{Referências}

Almeida, J. A. M. (2005). Sobre anamorfose: identidade e emancipação na velhice. Tese de Doutorado, Programa de Pós-graduação em Psicologia Social, Pontifícia Universidade Católica de São Paulo, SP.

Araújo, S. M. \& Cinalli, D. L. (2005). Trabalho e mundo da vida: a racionalidade capitalista presente na técnica, ciência e tecnologia. Revista Gestão Industrial, 1(4), 42-59.

Ciampa, A. C. (2001). A Estória do Severino e a História da Severina: um ensaio de Psicologia Social. São Paulo: Brasiliense.

Ciampa, A. C. (2002). Políticas de identidade e identidades políticas. In C. I. L. Dunker \& M. C. Passos (Orgs.), Uma psicologia que se interroga: ensaios (pp.120 - 135). São Paulo: Edicon.

Freitag, B. \& Rouanet, S. P. (1980). Habermas: sociologia. São Paulo: Ática.

Goffman, E. (1988). Estigma: notas sobre a manipulação da identidade deteriorada. Rio de Janeiro: LTC.

Habermas, J. (1999). Teoria de la Acción Comunicativa I. Racionalidad de la Acción y Racionalización Social. Buenos Aires: Taurus Humanidades.

Honneth, A. (2003). Luta por reconhecimento: a gramática moral dos conflitos sociais. São Paulo: Editora 34.

Lane, S. T. M. (1987). Prefácio. In A. C. Ciampa. A Estória do Severino e a História da Severina: um ensaio de Psicologia Social (pp.1-10). São Paulo: Brasiliense.

Lane, S. T. M. \& Sawaia, B. B. (Orgs.). (2006). Novas Veredas da Psicologia Social. São Paulo: Brasiliense; EDUC.
Lima, A. F. (2009). Da produção do não existente ao reconhecimento perverso: uma discussão sobre a persistência da racionalidade instrumental (politicamente correta) e a utopia do reconhecimento pós-convencional [Resumo]. In Associação Brasileira de Psicologia Social (Org.), Resumos de comunicações científicas, XVI Encontro Nacional da ABRAPSO (p.136). Maceió: ABRAPSO.

Lima, A. F. (2010). Metamorfose, anamorfose e reconhecimento perverso: a identidade na perspectiva da Psicologia Social Crítica. São Paulo: FAPESP; EDUC.

Lima, A. F. (2014). História oral e narrativas de história de vida: a vida dos outros como material de pesquisa. In A. F. Lima \& Lara, N. (Orgs), Metodologias de pesquisa em Psicologia Social Crítica (pp. 13-34). Porto Alegre: Sulina.

Lima, A. F. (2015). A teoria crítica de Jürgen Habermas. cinco ensaios sobre linguagem, identidade e Psicologia Social. Porto Alegre: Sulina.

Mead, G. H. (1973). Espiritu, Persona y Sociedad. Barcelona: Paidós.

Sennett, R. (1998). A corrosão do caráter: consequências pessoais do trabalho no novo capitalismo. Rio de Janeiro: Record.

Siebeneichler, F. B. (2003). Jürgen Habermas: razão comunicativa e emancipação. Rio de Janeiro: Tempo Brasileiro.

Agências de fomento: Nadir Lara Junior bolsista FAPESP (processo 2016/05322-4). Andrea Paula dos Santos Lara - bolsa CAPES DS.

Submissão em: 30/10/2016

Revisão em: 16/05/2017

Aceite em : 18/06/2017

Nadir Lara Junior é mestre e doutor em Psicologia Social PUC-SP. Pós-doutorando em Psicologia Clínica pela USP. Bolsista FAPESP.

Endereço: Rua Dona Saza Lattes, 472 B - Bairro Uberaba, Curitiba/PR, Brasil. CEP 81540-460 E-mail: nadirlj@hotmail.com

Andrea Paula Santos Lara é psicóloga, Mestre em Psicologia Social pela PUC-SP. E-mail: andreapaulasl@gmail.com 